\title{
DIÁLOGOS LITERÁRIOS: A CRIANÇA E AS RELAÇÕES PÓS-COLONIAIS
}

\section{LITERARY DIALOGUES: THE CHILD AND POST-COLONIAL RELATIONS}

Jhennefer Alves Macêdo ${ }^{1}$

Vanessa Neves Rimbau Pinheiro²

\begin{abstract}
Resumo: Tomando como objetos de estudo as obras Comandante Hussi (2006) e A bicicleta que tinha bigodes (2013), propomonos a apresentar um panorama das relações entre as literaturas africanas e as formulações pós-coloniais e analisar os personagens infantis das narrativas citadas, tendo como foco de discussão as suas representações enquanto sujeitos que se encontram situados numa experiência de opressão pós-colonial, dentro de seus contextos geográficos e históricos.
\end{abstract}

\begin{abstract}
Taking the works Comandante Hussi (2006) and A bicicleta que tinha bigodes (2013) as objects of study, we propose to present an overview of the relationships between African literature and post-colonial formulations and to analyze the children's characters of the narratives mentioned, having as focus of discussion their representations as subjects who are located in an experience of post-colonial oppression, within their geographical and historical contexts.
\end{abstract}

Palavras-chave: Literatura africana; Infância; Pós-colonialismo.

Keywords: African literature; Childhood; Post-colonialism.

\section{Introdução}

Muito embora já possua um vasto repertório de produção teórica, os estudos pós-coloniais ainda estão ganhando espaço no que concerne a sua formulação nas produções literárias. Para que haja uma designação de 'literatura pós-colonial', considera-se toda produção literária dos povos colonizados pelas potências europeias entre os séculos XV e XXI. Essas literaturas originam-se das experiências de colonização e suas principais abordagens giram em torno da criação de um contexto favorável para os povos que foram deixados à margem da literatura produzida durante a dominação colonial, visando alcançar, dessa forma, a recuperação das histórias silenciadas.

Além desse olhar para as histórias que não foram contadas, a estética literária do póscolonialismo apropria-se das estratégias de releitura e reescrita para aprofundar uma visão crítica da ideologia que forma o corpus literário produzido pelo colonizador. Nessas estratégias, os escritores,

1 Doutoranda no PPGL- UFPB. Mestre pela mesma universidade. Desenvolve pesquisas vinculadas aos seguintes temas: literatura infantil e juvenil, leitura, formação de leitores e leitura e ensino.

2 Doutora pelo programa de Pós-Graduação em Letras da Universidade Federal do Rio Grande do Sul (UFRGS), Área de Estudos Literários, Ênfase em Literaturas de Expressão Portuguesa. Atualmente, coordena o Grupo de Estudos Africanos na Universidade Federal da Paraíba (UFPB), onde atua como Professora Adjunta na graduação e na pós-graduação. Integra também o CEsA - Centro de Estudos sobre África, Ásia e América Latina, vinculado à Universidade de Lisboa. 
conscientes dos seus papéis de mestres do contexto pós-colonial, apropriam-se de textos oriundos das culturas coloniais, geralmente canônicos, aplicam uma leitura desconstrutivista aos textos escritos, problematizam o enredo, os personagens e a estrutura e recriam um novo texto que funcione como resposta pós-colonial à ideologia presente no primeiro texto. De acordo com Bonnici: "A finalidade da releitura pós-colonial consiste em demonstrar (1) o grau da contradição existente no texto, que subverte seus próprios pressupostos, ou seja, a civilização, a justiça, a estética e a sensibilidade, e (2) as estratégias e as ideologias coloniais." (2012, p.49).

Nesse sentindo, a expansão e a reformulação do campo crítico pós-colonial significaram, para o campo literário, um caminho para uma literatura autônoma, um processo de revisão das obras produzidas até então e da abertura de um novo tempo, abrindo espaço para que escritores africanos promovessem as suas publicações, as quais, em sua grande maioria, representaram a libertação para a voz do oprimido. Para Leite (2013, p. 36), esse fenômeno pós-colonial torna-se híbrido, por meio da sua coexistência pluralizada, as quais são resultantes dos sistemas culturais europeus e das antologias indígenas, impulsionando, dessa forma, a "(re)criação dos novos campos literários e das identidades locais”. A autora ainda problematiza essa enunciação e lugar da literatura nacional, ao dizer:

\footnotetext{
Não é possível regressar a uma pureza pós-colonial absoluta, tal como não é possível criar formações nacionais, totalmente, independentes das suas implicações históricas na empresa colonial. As literaturas africanas de língua portuguesa, com a criação dos seus campos literários específicos, relatam as narrativas desse impossível regresso ao passado, entretecendo, com sabedoria, a sua reinvenção. (LEITE, p. 36).
}

No que concerne a esse projeto de escrita pós-colonial, o mesmo está dividido em três etapas. A primeira etapa envolve os textos literários que foram produzidos por representantes do poder colonizador. Dentre as abordagens mais comuns nessas produções, destacam-se os costumes, a língua, a flora e a fauna. No entanto, há sempre uma sobreposição da metrópole em relação à colônia e do centro em relação à periferia. A segunda etapa reúne os textos literários produzidos pelos nativos, contudo, os mesmos ainda permaneciam sob supervisão imperial, já que possuíam uma educação da metrópole e se sentiam privilegiados por poder escrever na língua do europeu, esquecendo-se que se tratava, antes de tudo, de seu próprio colonizador, ou seja, nessa produção, muitas vezes, há a perpetuação dos paradigmas do colonizador sem que haja um olhar crítico para essa situação. Sobre as temáticas retratadas por esse segundo grupo e as problemáticas incutidas nessas produções, Bonnici (2012) esclarece:

Embora muitos dos temas (cultura mais antiga do que a europeia, a brutalidade o do sistema 
colonial, a riqueza de seus costumes, leis, cantos, e provérbios) abordados por esses autores estivessem carregadas de subversão, sem dúvida não podiam e não queriam perceber sua potencialidade. Além disso, a manutenção da ordem e as restrições impostas pela potência imperial não permitiam qualquer manifestação que pudesse indicar algo diferente dos critérios canônicos políticos (BONNICI, p. 22).

Em concordância como esse pensamento, o autor Hountondji (2008) levanta questionamentos que suscitam reflexões acerca da construção das pesquisas produzidas sobre a história africana, por determinados autores, pois, segundo ele, através desse olhar do outro, ainda impera um controle do ocidente, resultando em produções com conteúdos superficiais.

Em síntese, o desenvolvimento das literaturas pós-coloniais só veio a consolidar-se a partir do instante em que os autores africanos assumiram, abertamente, uma postura subversiva, por meio de suas produções ficcionais, cumprindo, dessa forma, com a tarefa de críticos pós-coloniais, questionando os legados coloniais e recuperando, através do "entre-lugar" dos seus personagens, as vozes culturais. Nesse momento, o texto literário produzido em África torna-se uma prática social, na qual o autor possui participação direta no discurso. Para Campos (2013):

A produção artística - aqui particularmente a Literatura - surge como parte do processo de consolidação das identidades nacionais, por meio de seu caráter de representação. Exemplo disso é a busca de expressão de identidade cultural que a literatura africana vem demonstrando, ao resgatar traços culturais preservados pela oralidade, e através de uma voz de engajamento social, o que confirma o caráter de representação da criação artística, sendo uma projeção que uma sociedade faz de si mesma, buscando representar a realidade, e não apenas reproduzi-la. (CAMPOS, 2013, p.2).

Ainda de acordo com o pensamento da autora, a historicidade das literaturas guineense, cabo-verdiana, angolana, são tomense e moçambicana está fundamentada em três alicerces, cuja compreensão foi desenvolvida ao longo do texto: A oralidade; O passado; A nação. Esses elementos interligam-se, relacionam-se e cumprem a função de construção de um sentido histórico. Essas literaturas africanas operam historiograficamente ao registrar acontecimentos, fenômenos sociais e culturais da natureza humana. São monumentos erguidos em memória do tempo (passado- presentefuturo) contra o esquecimento a que estão relegados os povos subalternos.

Além disso, as produções literárias conduzidas por esses autores seguem outro viés: o de denúncia. Seja ela de forma explicita ou implícita, é possível verificar que os textos tornaram-se um veículo para discutir e expor questões sociais e políticas que ainda vigoram nas ex-colônias africanas, locais que ainda imperam as amarras da opressão, dessa vez não mais imposta pelos primeiros 
colonizadores, mas por aqueles que parecem ter se deixado formar por suas influências e os seus jogos de poder : a classe política - assim como bem retratado em Os transparentes (2012), do escritor angolano Ondjaki.

Para abordar essas problemáticas, as relações desiguais entre colonizado e colonizador, em sua versão mais contemporânea, são expressas nas páginas das produções literárias endereçadas ao público infantil e juvenil. Inclusive, é nesse personagem, a criança, que está representando o “entre-lugar" da nação africana: o sujeito dominado que assume uma postura emancipatória. É válido ressaltar que essa postura pode ser assumida através da voz propriamente dita, seja por meio de protestos e reivindicações, ou da aplicação dela na expressão literária, utilizando-se, inclusive, da metalinguagem, usando a literatura para falar do poder da própria palavra, quando nas entrelinhas do texto ecoam os sons do desejo por liberdade.

\section{Diálogos Possíveis entre Ficção e Realidade:Aprofundando os Sentidos dos Textos}

Alteridade e identidade possuem definições convergentes. A primeira baseia-se na ótica da diferença, de ser outro. A segunda define-se tomando como parâmetro o conjunto de características que distinguem uma pessoa ou uma coisa e por meio das quais é possível individualizá-la. O sujeito colonial, o outro, na visão colonialista, é o objeto que resulta da construção imperialista, sendo definido como o subalterno. Para Hall (1996), as categorias coloniais do saber tinham o poder de nos fazer ver e nos fazer sentir como 'outros' e esse tipo de saber é interno e não externo. Esse empreendimento colonial foi tão profundo que condicionou o sujeito colonial a agir apenas como objeto, tornando, dessa forma, o mundo dos subalternos limitado. O domínio imperial limitou a expressão do homem e conseguiu restringir, por muito tempo, qualquer indício de cunho revolucionário.

Para Foé (2013), essa imobilidade do nativo muito está ligada à ausência de questionamento por parte do colonizado, algo que resulta na permanência dos laços de subalternização, mesmo após a saída do império colonial. Nesse ponto, observamos que o próprio sujeito africano, em determinados momentos, permitiu tornar-se objeto regido pelos ideais do opressor e não os questionar, aceitando as únicas formas de diálogo existente entre dominador - dominado: violência, opressão, insulto, estigmatização, ódio e desprezo.

No entanto, Bonnici (2012) ressalta que ser colonizado implica em ser sujeito, o que necessariamente envolve a rebeldia, também ligada à recuperação da própria identidade:

O colono-colonizador faz a história e sabe disso. Como se refere constantemente à história de sua metrópole mostra que ele é uma extensão daquele país. Portanto, a história que ele escreve não é a história do país que ele saqueia, mas a história de seu pais, no que diz respeito 
a tudo o que ele rouba e violenta e esfaima. A imobilidade na qual o nativo está fixado pode ser questionada se ele mesmo decide pôr um fim à história da colonização - a história da pilhagem - e fazer emergir a história da nação - a história da colonização. (BONNICI, p.42).

É seguindo esse viés que as narrativas Comandante Hussi (2006) e A bicicleta que tinha bigodes (2013) constroem um paralelismo com essa dualidade que circunda a nação africana em seus diferentes contextos, a exemplo de Angola e de Guiné-Bissau: ser objeto ou ter voz? Para compreendermos a exposição de conflitos da dicotomia de exploração entre colonizador-colonizado, antes, é preciso ressaltar que dentre as principais exigências estabelecidas pelo projeto colonial, seja ele estrangeiro ou nacional, está, por parte dos povos colonizados, o da aceitação da condição de dominados. E essa aceitação, assim como já discutido anteriormente, em muitas situações, só pode se efetivar pelo silêncio e pela passividade dos subalternos. Todavia, conforme também já pontuado, $\mathrm{o}$ ato de olhar e de pensar criticamente pode representar a quebra de ciclos opressores, algo que fica evidenciado, ainda que, em certos trechos, de forma implícita, nas obras analisadas a seguir.

Inicialmente, na narrativa Comandante Hussi (2006) observamos uma nova sociedade que se formava nos países africanos de língua portuguesa e que reagia frente os esquemas ditatoriais. Essa reação está intimamente ligada ao conceito de rebeldia, o qual é mencionado por Bonnici (2012). Assim como Angola, Guiné Bissau enfrentou contínuas lutas para erguer a nação. O país passou por sucessivos golpes militares que desestabilizou a política e a economia dos guineenses. Exemplo disso foram os onze de meses de guerra civil em 1998. É nesse contexto histórico de onze meses de guerra civil que o jornalista Jorge Araújo e o ilustrador Pedro Sousa tentam mostrar, através do texto ficcional, a vida de quem precisou se refugiar para o interior de Bissau e daqueles que pegaram nas armas.

No contexto da obra Comandante Hussi (2006), o narrador utiliza-se da estratégia da paródia, aproximando-se do universo infantil, para narrar a disputa político-militar do Presidente Nino Vieira (Comandante Trovão) e o Brigadeiro Ansumane Mane (Brigadeiro Raio de Sol). Evidencia-se na narrativa a adesão do narrador às forças lideradas pelo Brigadeiro, ou seja, a voz do povo, na qual observamos que a própria maneira como o menino Hussi chama o "Brigadeiro Raio de Sol" faz referência ao raiar de um novo tempo; enquanto o "Comandante Trovão" continua a representar a permanência da noite colonial e das névoas opressoras que encobriram o direito de expressão dos subalternos, isto é, uma falácia da democracia.

$\mathrm{Na}$ narrativa, o golpe é representado quando um ex-combatente de guerra, o "Brigadeiro Raio de Sol", que morava em uma casa afastada da cidade e que tinha feito dela seu próprio exílio, resolveu sair para ver o que estava acontecendo, uma vez que a população estava tão revoltada com o governo e pedia para ele, como combatente que foi, para solucionar as injustiças, a exemplo da escassez de alimentos, educação e saúde, realidade que destoava completamente das promessas outrora proclamas: 
melhoria de vida nas principais estruturas sociais, Ciente da situação precária, "Brigadeiro Raio de Sol" resolve declarar guerra, a fim de encerrar as privações que o povo estava enfrentando. Nessa guerra, os rebeldes entram em confronto com as forças presidências. Entre esses representantes do povo está o próprio menino Hussi, que, preocupado com pai, recusa-se a ficar refugiado com a família e retorna para o cenário de combate, acabando por se inserir na guerra, tornando-o, então, um meninosoldado.

É nesse âmbito que observamos a dicotomia sujeito-participativo/sujeito-objeto existente no núcleo da consciência da própria população, com suas singularidades, dos países africanos de língua portuguesa, em relação ao seu papel social, pois enquanto em Comandante Hussi (2006) observase um desejo latente por liberdade, desejo esse que impulsiona a luta, mesmo que essa represente a perda de inúmeros objetos materiais e da separação com a família, em A bicicleta que tinha bigodes (2013) nos deparamos com um silencio ensurdecedor por parte da população frente aos problemas sociais, algo que denota uma possível "aceitação" da condição de oprimido, com raras exceções, como poderemos visualizar mais adiante.

Ainda no início do livro percebemos uma referência direta ao contexto político e social que perpassa o dia a dia dos personagens:

Quando ouvi a notícia no rádio, que iam dar uma bicicleta bem bonita, amarela, vermelha e preta, lembrei-me logo de falar com o tio Rui. Era um concurso nacional com prêmio de uma bicicleta colorida que já apareceu na televisão, mas nesse dia na nossa casa não havia luz. (ONDJAKI, 2013, p.10).

A falta de luz, mencionada nesse trecho, revela uma situação corriqueira entre os angolanos. Outra problemática ressaltada faz referencia à corrupção; assim que anunciam o concurso, o protagonista ouve a seguinte afirmação dos seus colegas: "todos me gozavam a dizer que essa bicicleta já deve ter dono, já que sabem quem é que vai ganhar.” (ONDJAKI, p.10).

Presenciamos, já neste ponto, os reflexos de uma sociedade angolana silenciada, ou como aponta Bonnici (2012), daquela que aderiu ao projeto do colonizador e aceitou seu lugar de colonizado. Portanto, a ausência de diálogos de confrontação relaciona-se às imagens de sujeitos-objetos, sendo resultantes de um produto colonial e que se tornam condescendentes aos desmandos das autoridades ditatoriais.

Toda a trama é tecida sempre com a utilização de metáforas. Logo no início, é apresentada uma situação de conflito: o sapo de estimação de Isaura - moradora mirim do bairro, e grande amiga do narrador- é atropelado e morto por um jipe militar, que está sendo conduzido por um homem chamado Nove - assim chamado por ter matado nove pessoas - e que tinha como passageiro o General Dorminhoco. Esse feito revela como era corriqueiro o convívio dos moradores com jipes e 
militares sempre circulando na rua, bem como o eram os casos de violência. Além disso, em outras passagens, nos é mostrada a escassez de comida do povo angolano.

De modo geral, como observamos, brevemente, nos trechos mencionados, os autores das narrativas, em diferentes contextos, projetam os abusos dos governos ditatoriais, mencionando, por exemplo, inúmeros casos de violência e precariedades sociais. No entanto, de forma a revelar a ausência de uma homogeneização nas experiências pós-guerra dos diferentes países africanos, na narrativa escrita por Ondjaki, não conseguimos constatar qualquer indício de reação, por parte dos adultos, contra as realidades exploradoras, imperando, dessa forma, a ausência de fala, pois é clara a recusa do povo em lutar por uma reforma política. Vivendo dentro dos parâmetros pós-coloniais, a passividade frente aos esquemas de dominação permite que suas vidas continuem sendo manipuladas de tal maneira que eles já não se questionam sobre o lugar subalterno que ocupam, apenas o aceitam e aprendem a conviver com as imposições dos regimes militares - referência direta às discussões apresentadas no início deste artigo.

Levando consideração a violência gratuita que acontece no cenário pós-guerra, em Angola, essa recusa de posicionamento pode ser considerada inaceitável. A narrativa do angolano ainda projeta a violência do seu governo e reflete, sejam em episódios domésticos ou no relacionamento entre os personagens, os episódios sociopolíticos, fazendo um paralelismo com a brutalidade dos regimes militares e a corrupção onipresente em Angola.

Esse esquema do complexo colonizador-colonizado só apresenta ruptura em $A$ bicicleta que tinha bigodes (2013), por meio da quebra do silêncio feita pela criança. É nessa ruptura que podemos observar uma aproximação das duas narrativas, uma vez que personagens infantis, através da imaginação, representam a nova Angola e a nova Guiné-Bissau. Duas crianças que, por intermédio de elementos imaginários e das histórias escritas, expressam a sua revolta contra a dominação estrangeira e contra o inferno social que estavam fadadas a viver, tornando-se sujeitos emancipatórios do seu tempo.

Assim como já mencionado, a história dos povos africanos é marcada pela falta de expressão cultural e pela censura e bloqueio da identidade nacional. A colonização, além de marginalizar o povo, também deixou sérias marcas nas produções literárias dos países lusófonos, resultando no silenciamento e na invisibilidade de milhões de africanos escravizados e de seus descendentes. A respeito disso:

São notórias a proibição colonial da escrita e a contenção pelo poder ao ensino, à expressão identitária e à literatura. Em muitos casos, o silêncio nativo é tão abrangente que fica a convicção de que a pessoa colonizada foi como que totalmente riscada pela escrita ocidental. (BONNICI, p.325). 
Todavia, essa censura não durou para sempre e nem conseguiu calar todas as vozes, a exemplo dos sujeitos que resistiram de diferentes maneiras. Como prova disso, levando em consideração as questões expostas acima, podemos citar os personagens infantis, das narrativas analisadas, que conseguiram romper com o silêncio e contar a sua própria história. Nas narrativas, os traços textuais e imaginários vão muito além da fala e representam tanto as manifestações do sujeito, enquanto seres conscientes da sua condição, mas não satisfeitos com ela; quanto um hiato, entre o sonho libertário de uma nação, que constrói pontes, através da palavra e do sonho, para escapar do pano de fundo devastador. Sem dúvida, a simbologia apresentada pelos autores na construção desses dois personagens infantis revela-se como uma alegoria sobre a realidade e a situação da África.

Em comandante Hussi (2006), o protagonista mirim, antes de a guerra eclodir, possuía uma bicicleta velha, a qual tinha um grande valor afetivo, pois tinha sido o único presente, em toda a sua vida, que seu pai tinha conseguido lhe dar. A bicicleta, em seus sonhos, ganhava vida, forma e até voz: "Ainda só ia no terceiro sono, a meio de um sonho cor-de-rosa, deslumbrado a ver sua bicicleta voar com elegância de uma borboleta, escoltada por duas imponentes águias reais. (ARAÚJO, 2006, p.15).

Diferente de Hussi, em A bicicleta que tinha bigodes (2013), o menino angolano não consegue seu objeto tão esperado, mas, durante a preparação para tentar possuí-lo, embarca em um universo imaginário. Os anseios infantis ficam evidenciados pelo desejo de conquistar algo até então não alcançado pela falta de condições financeiras.

Essas fantasias, embora inocentes, representam, na realidade, as aspirações dos sonhos de uma nação em poder conquistar horizontes que não estavam ao alcance. Nos sonhos de Hussi e do menino angolano, ao tornar-se um objeto inanimado, a bicicleta representa uma fonte de escape que suavizava a carga das privações sociais que Guiné-Bissau e Angola enfrentavam. Pensar em uma realidade diferente era algo apenas permitido através de uma bicicleta, objeto esse que tem a função de conduzir seu passageiro para outros lugares, ou seja, metaforicamente, libertar o povo da situação opressora

No próprio desenrolar da narrativa Comandante Hussi (2006), as forças militares do "Comandante Trovão" passam a atribuir a vitória dos rebeldes comandados pelo "Brigadeiro Raio de Sol" ao fato deles possuírem essa bicicleta, um objeto enxergado pelas tropas presidências como sendo um detentor de forças sobrenaturais, tornando-se, desse modo, a mola propulsora para a conquista do povo.

Ao tomar nota dessa arma secreta do inimigo, o "Comandante Trovão" ordena uma missão militar para que o objeto seja destruído, extinguindo, dessa forma, com a força do povo. No mesmo trecho em que esse fato é narrado, faz-se referência a outro episódio em que o governante mandou matar um professor que tinha ousado explicar aos alunos o significado da palavra liberdade.

Observa-se no contexto político da narrativa A bicicleta que tinha bigodes (2013) uma crítica ao governo angolano, explicitada quando o menino, após não ganhar a tão sonhada bicicleta, resolve 
escrever uma carta para o presidente. Nesse episódio, constata-se, implicitamente, a construção de um pedido para que o presidente olhe para o povo, e se não puder dar uma bicicleta grande, ao menos der uma pequenininha para cada um.

Ao fim da narrativa, o Tio Rui, um personagem que homenageia um dos principais escritores angolanos, Manoel Rui, pelo qual o escritor Ondjaki nutre uma grande admiração, descreve, de maneira poética, a esperança que os velhos depositam nas crianças para a reconstrução de uma angola igualitária e livre:

- Gostas de estrelas?

- Gosto bué, tio Rui. Brilham sem gastar a pilha. Só nunca consegui entender a cor delas.

- As estrelas não têm cor, são como as pessoas.

- Eu pensei que a cor das pessoas ficava na pele delas.

- Não. A cor das pessoas fica nos olhos de quem as olha.

- Então eu posso escolher a cor que eu quero ver, tio?

- Vocês podem.

- Nós quem?

- As crianças.

- Tio Rui, as estrelas têm dono?

- Têm, sim.

- São de quem?

- São do povo.

(ONDJAKI, p.86).

Ao longo das experiências dos personagens infantis, nas duas narrativas, é possível visualizar o contraste entre realidade e sonho. As crianças, por meio de suas histórias, sejam elas reais ou imaginárias, lutam para alcançar novas possibilidades dentro de países com inúmeros problemas. De modo a estabelecer paralelo com os dizeres de Leite (2013), essa luta e resistência são "uma condição indispensável para a existência dos homens e mulheres que tornam possível a transformação radical da sociedade.

Essa imaginação infantil também faz referência à capacidade de pensar, que, durante os processos de dominação, é a primeira ferramenta humana a ser bloqueada, buscando alienar o povo, pois sabe-se que quando o homem toma consciência do poder de seu pensar, os caminhos que revertem as posições entre explorador e explorado são encontrados.

Assim como exposto, Angola e Guiné-Bissau foram colônias portuguesas que, como toda colônia, ainda que por via de diferentes manifestações, sofreram com as vontades impostas pelos seus colonizadores, como exploração das riquezas naturais e imposição cultural. Embora tenham alcançado 
a independência, ainda tiveram que enfrentar conflitos políticos internos, os quais deixaram cicatrizes na população: milhões de mortos e uma realidade social com rastros da guerra, de preconceito e de miséria.

Contudo, embora o colonialismo e seus vestígios tenham ofuscado, por muito tempo, as esperanças libertárias e deixado a população sob o jugo da opressão, ao longo da leitura das narrativas infantis selecionadas como corpus desse estudo, ficou evidente a existência de uma ruptura no posicionamento dos personagens, evidenciando, de forma contundente, as semelhanças com as populações de seus países: inicialmente, condicionados aos acontecimentos dirigidos pelas autoridades dominantes; posteriormente, buscando sua liberdade seja pela exigência de que sua voz seja ouvida, por meio de protestos e guerras, seja pela própria expressão literária, mostrando um novo florescer do nativo descolonizado.

Os enredos, apesar de apresentarem contextos de guerra, mostram, com muita sensibilidade, que o ambiente de brutalidade não apagou o sonho de mudanças e de transformações sociais. Esses sonhos são manifestados pelos anseios infantis, ressaltando que o desejo dos fortes brada por intermédio das vozes daqueles considerados mais fracos. A recuperação dessa voz, nas palavras de Bonnici (p. 248), evidencia "a maneira através da qual as experiências não faladas e reprimidas podem ser faladas.". Uma busca por libertação e pelo direito de se sentirem como sujeitos, mas não mais no sentido de submissos ou de objetos.

Esses sonhos, nas narrativas, são conduzidos pelo fio da imaginação, uma característica inerente ao universo infantil e que está intrinsecamente ligada à capacidade de criar novos mundos. Nessa perspectiva, os dois livros analisados mostram esse universo imaginário, criado por seus protagonistas, que acabam por adicionar leveza e os permitem escapar das tensões sociais que os circundam.

Por fim, por meio das análises, constatamos que, no contexto das obras, os personagens infantis são as alegorias das relações pós-coloniais, estando diretamente relacionados à significação do processo de formação e mutação identitária, tanto da escrita literária africana quanto da própria nação.

\section{Referências}

ARAÚJO, Jorge. Comandante Hussi. São Paulo: Ed. 34, 2006.

BONNICI, Thomas. O pós-colonialismo e a literatura: estratégias de leitura. Maringá: Eduem, 2012.

CAMPOS, Josilene Silva. Poesia Moçambicana e a Escrita da História. In: XI Encontro Regional de História Anpuh, 2015, Goiás. Anais (on-line). Goiás, v.11, n.3, 2016. Disponível em: <file:///C:/Users/Jhennefer/Downloads/400118844-1-PB.pdf>. Acesso em: 15 Jan. 2018. 
Disponível em: <http://www.revistaabril.uff.br/index.php/revistaabril/article/view/268>. Acesso em: 10 Jan. 2018.

FOÉ, Nkolo. África em diálogo, África em autoquestionamento: universalismo ou provincialismo? "Acomodação de Atlanta” ou iniciativa histórica? Educar em Revista, n..47, enero-marzo, 2013. Disponível em: < http://revistas.ufpr.br/ educar/article/view/31332/20037>. Acesso em: 20 Dez. 2017.

HALL, Stuart. Identidade Cultural e Diáspora. Revista do Patrimônio Histórico e Artístico Nacional, n.24, 1996. Disponível em: <http://docvirt.com/docreader.net/DocReader.aspx?bib=reviphan\&pagfis=8697>. Acesso em: 12 Jan. 2018.

HOUNTONDJI Paulin J. Conhecimento de África, Conhecimentos africanos: duas perspectivas sobre os Estudos Africanos. Revista Crítica de Ciências Sociais, Coimbra n. 80, 2008. Disponível em: <http://journals.openedition.org/ rccs/699>. Acesso em: 02 Dez. 2017.

LEITE, Mafalda. Literaturas africanas e formulações pós-coloniais. Lisboa: Edições Colibri, 2013.

ONDJAKI. A bicicleta que tinha bigodes. Rio de Janeiro: Pallas, 2013.

. Os transparentes, $2^{\circ}$ edição. Córdova: Editorial Caminho, 2012. 